
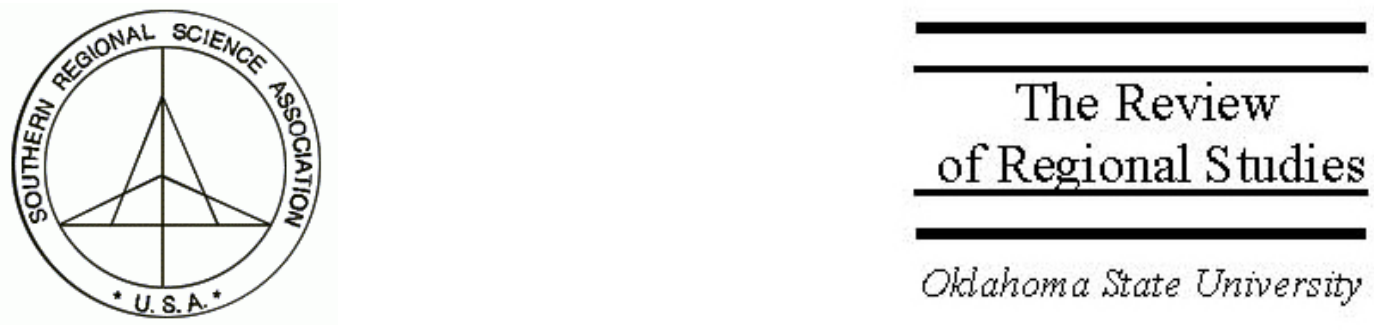

\title{
On the Sraffa-Leontief Model
}

\author{
Michael Sonis \\ Department of Geography, Bar Ilan University, 52900, Ramat-Gan, Israel and Regional \\ Economics Applications Laboratory, University of Illinois, 607 South Mathews, \#220, \\ Urbana, Illinois, 61801-3671, email: sonism@mail.biu.ac.il
}

Geoffrey J.D. Hewings

Regional Economics Applications Laboratory, University of Illinois, 607 South Mathews, \#220, Urbana, Illinois, 61801-3671, email: hewings@uiuc.edu

\begin{abstract}
In this paper we consider the matrix forms of the Sraffa-Leontief income distribution model $p x=(1+r) p A x+w^{*} p(I-A) x$ introduced by Steenge $(1995,1997)$. We will explore the equivalence between these matrix forms and the set of simpler models, including the Sraffian condition of linear relations between the rate of profits $r$ and wage rate $w^{*}$. Further, we will evaluate the condition that the price vector $p$ and the commodities vector $x$ are the left-hand and the righthand eigenvectors of the matrix $A$ of direct inputs and that these vectors are the fixed points of the Sraffian standard commodities-standard prices matrix. We will then explore links between the Sraffa-Leontief system and the multiplier product matrix (MPM) for the matrix $A$ to consider new insights generated through visualization with the help an artificial economic landscape. Furthermore, the connections between MPM and the Sraffian standard commodities-standard prices matrix and their minimal information properties are proven.
\end{abstract}

Keywords: Sraffa-Leontief income distribution model; Multiplier product matrix; Sraffian standard commodities-standard prices matrix; Minimum information properties.

JEL classification: C67; D51; B41

Authors would like to thank Professor Albert Steenge for attracting our attention to study of Sraffa models and for his kind encouragement and help. We are also grateful to Professor Heinz Kurz for pointing out some errors in an early draft of this paper. Chokri Dridi provided the computational expertise to realize the empirical examples. 


\section{INTRODUCTION}

The contributions of Sraffa (1960) to the understanding of economic structure have been significantly advanced in recent years by the interpretative assessments of Steenge $(1995,1997)$. In this paper, these interpretations are complemented with some additional modifications that attempt to simplify the presentation of the Sraffa-Leontief system. In the next section, the standard Sraffian model is presented and some of the initial modifications are outlined. In Section 3, the concept of the multiplier product matrix (MPM) is introduced but in a modified form; instead of considering the Leontief inverse matrix, the MPM methodology is applied to the matrix of direct coefficients to afford a direct link with the Sraffa system. In Section 4, the minimum information properties of the MPM and Sraffian matrix are presented and are shown to be directly related in Sections 5 and 6. Section 7 provides an empirical example from an input-output table for the Chicago metropolitan region. We conclude with some brief summary remarks and suggestions for further extensions.

\section{THE SRAFFIAN MODEL}

\subsection{Sraffian Prices Decomposition Matrix Primary Model and Commodities Decomposition Matrix Dual Model}

The simplest and most obvious way to construct the Sraffian income distribution model is as follows (cf. Pasinetti 1977; see also Kurz and Salvadori 1995 for a more extensive treatment): the input-output model is defined in the usual manner.

$$
x=A x+f,
$$

where $x$ is a vector of gross output, $A$ the matrix of input coefficients, and $f$ is a vector of final demand.

Introducing the vector of prices $p$ we obtain:

$$
p x=p A x+p f
$$

where it is conventionally assumed that the price of final demand is defined by the amount of labor imbedded in gross output:

$$
w l x=p f
$$

(We assume further that $w=1$, i.e., $l x=p f$.) Income distribution theory requires (see Pasinetti 1977, p.72-73, (V.3.1a)):

$$
p=(I+r) p A+w^{*} l,
$$

where $r$ is the uniform rate of profits and $w^{*}$ is the wage rate and $0 \leq w^{*} \leq 1$. 
From (2), (3), and (4) the Sraffa-Leontief income distribution model may be obtained:

$$
p x=(1+r) p A x+w^{*} p(I-A) x .
$$

This scalar model can be derived from the price decomposition matrix primal model:

$$
p=(1+r) p A+w^{*} p(I-A),
$$

or from the commodities decomposition matrix dual model:

$$
x=(1+r) A x+w^{*}(I-A) x
$$

by post-multiplication of (6) on $x$ and pre-multiplication of (7) on $p$.

\subsection{Sraffian Matrix and Decomposition of the Matrix A of Direct Inputs}

Consider a non-negative matrix, $A$, of direct input coefficients. (In the following, it is not necessary to adopt the usual assumption of decomposability and primitivity of matrix A.) From the theory of non-negative matrices (see, for example, Horn and Johnson 1985, p. 503), it follows that there are non-negative eigenvectors (left hand and right hand) $p^{*}$ and $x^{*}$ of $A$ corresponding to a non-negative eigenvalue $\mu$.

$$
p^{*} A=\mu p^{*}, A x^{*}=\mu x^{*}
$$

such that $\mu$ is a simple eigenvalue.

It is well known that if the sum of the elements of each column of the matrix of direct inputs is less than 1 and, of course, greater than 0 , then the maximum eigenvalue $\mu$ is in the interval $0 \leq \mu<1$. This follows from the well-known inequality for the spectral radius $\rho(A)$ of eigenvalues of positive matrix $A$ (see, for example, Horn and Johnson 1985, p. 346):

$$
\min _{i} \sum_{j} a_{i j} \leq \rho(A) \leq \max _{i} \sum_{j} a_{i j}
$$

The simplicity of $\mu$ means that the eigenspaces of all left-hand and right-hand eigenvectors corresponding to $\mu$ are one-dimensional spaces, i.e., each left-hand eigenvector is proportional to $p^{*}$, and each right hand eigenvector is proportional to $x^{*}$.

Let us assume (following Steenge 1995, p. 57) that

$$
p^{*} x^{*}=1
$$


and consider the matrix $S=x^{*} p^{*}$. This matrix will assume a major role in the subsequent analysis, and it will be referred to as the Sraffian matrix with the vector $x^{*}$, the vector of standard commodities, and the vector $p^{*}$, the vector of standard prices. Note that this definition of standard commodities is different from the conventional Sraffa definition: Sraffa labeled as standard commodities the vector of final demand $f^{*}$ generating the gross output $x^{*}$ :

$$
f^{*}=x^{*}-A x^{*}=(1-\mu) x^{*} .
$$

For standardization, we will assume a constant value for the Sraffian standard commodity

$$
p f^{*}=p^{*} f=p^{*} f^{*}=(1-\mu) .
$$

Condition (10) means that these vectors are fixed points of the transformation $S$ :

$$
p^{*} S=p^{*}, S x^{*}=x^{*} .
$$

The conditions (8) imply that

$$
A S=S A=\mu S .
$$

Consider further $C=I-S$. Obviously

$$
\begin{aligned}
& S^{2}=S, C^{2}=C, C S=S C=0, \\
& A S=S A=\mu S, A C=C A
\end{aligned}
$$

i.e.,

$$
A=A(S+C)=\mu S+C A .
$$

Goodwin (1983) and Steenge (1995) used, in their considerations, the complicated fine structure (Perronean properties) of the spectrum and spectral decomposition of the matrices with non-negative components. Alternatively, use will be made here only of the decomposition (15), the Perronean eigenvector - corresponding to the larger eigenvalue -and the one-dimensional eigenspace that splits from the eigenvalues structure. This splitting essentially will simplify the proofs. 


\subsection{Sraffa's Linear Wage-Profit Trade-Off}

If in the Sraffian model (5), an arbitrary vector of prices $p$ and gross output equal to $x^{*}$ are chosen, then substituting gross output $x$ by the eigenvector $x^{*}$ in the SraffaLeontief model (5), using (8) and dividing by $p x^{*}$ one obtains:

$$
1=(1+r) \mu+w^{*}(1-\mu)
$$

This relationship implies the Sraffa linear relation between the rate of profits $r$ and the wage rate $w^{*}$ (see Sraffa 1960, p. 22; see also Pasinetti 1977, p. 115):

$$
r=\left(1-w^{*}\right) \frac{1-\mu}{\mu}
$$

Obviously, the maximal rate of profits corresponding to the case $w^{*}=0$ is equal to:

$$
r_{\max }=\frac{1-\mu}{\mu}
$$

The same situation will occur when the choice is made of an arbitrary gross output $x$ and the vector of prices $p^{*}$.

\subsection{Equivalence Theorems for the Primary Sraffa-Leontief Matrix Model}

The linear wage-profit trade-off (equations 17 - 18) implies the following statements.

Theorem P1. If $(\alpha)$ in the Primary Sraffa-Leontief matrix model (6) $w^{*} \neq 1$, then $(\beta)$ in this model is equivalent to

$$
\left\{\begin{array}{l}
1-w^{*}=\mu\left(1+r-w^{*}\right) \\
\mu p=p A
\end{array}\right.
$$

Proof: $(\alpha) \Rightarrow(\beta)$.

The model (6) can be rewritten in the following form:

$$
\left(1-w^{*}\right) p=\left(1+r-w^{*}\right) p A
$$

and, as shown above in Section 2.3, implies $(17-18)$. The conditions $(17-18)$ mean that:

$$
1-w^{*}=\mu\left(1+r-w^{*}\right)
$$


and this implies, after substitution in (20), that:

$$
\begin{aligned}
& \mu p=p A \\
& (\beta) \Rightarrow(\alpha) .
\end{aligned}
$$

Contrarily, if the conditions (19) are true, then multiplying (22) by $1+r-w^{*}$ and using (21) one obtains (20); this concludes the proof of equivalence.

\subsection{The Steenge Equivalence Condition}

The following proposition is the reformulation and clarification of the considerations of Steenge (1995, pp. 63-66). Steenge proved that in Propositions P1 and D1, both conditions in $(\beta)$ are equivalent in the Sraffa model. In his proof, he used the fine structure of the all eigenvalues and eigenvectors of positive matrices.

Proposition P1. If $(\alpha)$ in the Primary Sraffa-Leontief matrix model (7) $w^{*} \neq 1$, then $(\beta)$ this model is equivalent to

$$
\left\{\begin{array}{l}
1-w^{*}=\mu\left(1+r-w^{*}\right) \\
p=p S
\end{array} .\right.
$$

Proof: $(\alpha) \Rightarrow(\beta)$

If condition (22) is true then

$$
\mu p C=\mu p(I-S)=\mu p-\mu p S=p A-\mu p S=p(A-\mu S)=p A C .
$$

This condition means that the vector $p C$ is a left-hand eigenvector for $A$; and because the eigenspace corresponding to the simple eigenvalue $\mu$ is one-dimensional, then the vector $p C$ is proportional to $p^{*}$, i.e., there is a number $\lambda$ such that $p C=\lambda p^{*}$. Using (9), we obtain $p C=\lambda p^{*} S$. Therefore $p C=p C^{2}=\left(\lambda p^{*} S\right) C=0$. Thus,

$$
\begin{aligned}
& p=p S+p C=p S \\
& (\beta) \Rightarrow(\alpha) .
\end{aligned}
$$

Conversely, if $p=p S$, then $p C=0$, and $p C A=p A C=0$. Therefore

$$
p A=p(\mu S+A C)=\mu p S=\mu p .
$$

Thus, (23) is equivalent to (19). 


\subsection{Equivalence Theorems for the Dual Sraffa-Leontief Matrix Model}

Analogously, the following statement can be proven for the Dual Sraffa-Leontief model (7).

Theorem D1. If $(\alpha)$ in the Primary Sraffa-Leontief matrix model (7) $w^{*} \neq 1$, then $(\beta)$ in this model is equivalent to

$$
\left\{\begin{array}{l}
1-w^{*}=\mu\left(1+r-w^{*}\right) \\
\mu x=A x
\end{array}\right.
$$

Proposition D1 (Steenge, 1995). If $(\alpha)$ in the Dual Sraffa-Leontief matrix model (7) $w^{*} \neq 1$, then $(\beta)$ this model is equivalent to

$$
\left\{\begin{array}{l}
1-w^{*}=\mu\left(1+r-w^{*}\right) \\
x=S x
\end{array} .\right.
$$

\section{THE MULTIPLIER PRODUCT MATRIX (MPM)}

\subsection{The Definition of MPM}

In this section, a connection between the Sraffa standard commodity system and the multiplier product matrix will be revealed. The definition of the direct inputs multiplier product matrix (MPM) is as follows: let $A=\left[a_{i j}\right]$ be a matrix of direct inputs in the input-output system, and let $m_{\bullet j}$ and $m_{i}$. be the column and row sums of this matrix. Following Chenery and Watanabe (1958) these are defined as:

$$
m_{\bullet j}=\sum_{i=1}^{n} a_{i j}, \quad m_{i} \cdot=\sum_{j=1}^{n} a_{i j}
$$

Let $V$ be the global intensity of the matrix $A$ :

$$
V=V(A)=\sum_{i=1}^{n} \sum_{j=1}^{n} a_{i j}
$$

Then, the input-output multiplier product matrix (MPM) is defined as: 


$$
M=M(A)=\frac{1}{V}\left\|m_{i} \cdot m_{\bullet j}\right\|=\frac{1}{V}\left(\begin{array}{c}
m_{1 \bullet} \\
m_{2} \\
\vdots \\
m_{n \bullet}
\end{array}\right)\left(\begin{array}{llll}
m_{\bullet 1} & m_{\bullet 2} & \cdots & m_{\bullet n}
\end{array}\right)=\left[m_{i j}\right]
$$

Introducing the vectors of column and row sums:

$$
M_{r}(A)=\left(\begin{array}{c}
m_{1 \bullet} \\
m_{2} \\
\vdots \\
m_{n \bullet}
\end{array}\right) ; M_{c}(A)=\left(\begin{array}{llll}
m_{\bullet 1} & m_{\bullet 2} & \cdots & m_{\bullet n}
\end{array}\right)
$$

one obtains the following expression of MPM matrix:

$$
M(A)=\frac{1}{V} M_{r}(A) M_{c}(A) .
$$

The properties of the MPM will now be considered in the context of the following issues: (i) the hierarchy of backward and forward direct inputs linkages and their economic landscape associated with the cross-structure of the MPM; and (ii) the minimum information properties of the MPM.

\subsection{Economic Cross-Structure Landscapes of MPM and the Rank-Size Hierarchies of Input Backward and Forward Linkages}

In this subsection, the main notions and results of the Rasmussen-Hirshman key sector analysis of backward and forward linkages for the direct and indirect inputs of Leontief inverse will be transferred to the case of direct inputs. To this end, the transformation in the classical theory of key sectors (cf. Sonis, Hewings, and Guo 2000; Sonis and Hewings 1999) involves replacement of the Leontief inverse by the consideration of the matrix of direct inputs, A. Following this analogy and the ideas of Rasmussen (1956), two types of indices will be defined, drawing on entries in the matrix $A$ of direct inputs:

1. Power of dispersion of direct inputs for the backward linkages, $D I B L_{j}$, as follows.

$$
\begin{gathered}
D I B L_{j}=\frac{1}{n} \sum_{i=1}^{n}{ }_{i j} / \frac{1}{n^{2}} \sum_{i, j=1}^{n} a_{i j}= \\
=\frac{1}{n} m_{\bullet j} / \frac{1}{n^{2}} V=m_{\bullet j} / \frac{1}{n} V
\end{gathered}
$$


and

2. The indices of the sensitivity of dispersion of direct inputs for forward linkages, $D I F L_{i}$, as follows.

$$
\begin{array}{r}
\operatorname{DIFL}_{i}=\frac{1}{n} \sum_{j=1}^{n} a_{i j} / \frac{1}{n^{2}} \sum_{i, j=1}^{n} a_{i j}= \\
=\frac{1}{n} m_{i \bullet} / \frac{1}{n^{2}} V=m_{i \bullet} / \frac{1}{n} V
\end{array}
$$

A direct inputs key sector, $K$, is usually defined as one in which both indices are greater than 1.

The definitions of backward and forward linkages provided by (32) and (33) imply that the rank-size hierarchies (rank-size ordering) of these indices coincide with the ranksize hierarchies of the column and row sums. In this connection, it is important to underline that the column and row sums for MPM are the same as those for the matrix of direct inputs $A$ :

$$
\begin{aligned}
& \sum_{j=1}^{n} m_{i j}=\frac{1}{V} \sum_{j=1}^{n} m_{i \bullet} m_{\bullet} j=m_{i \bullet} \\
& \sum_{i=1}^{n} m_{i j}=\frac{1}{V} \sum_{i=1}^{n} m_{i \bullet} m_{\bullet j}=m_{\bullet j}
\end{aligned}
$$

Thus, the structure of the MPM is essentially connected with the properties of sectoral direct inputs backward and forward linkages.

The structure of the matrix $M$ can be ascertained in the following fashion: consider the largest column sum $m_{\bullet j}$ and the largest row sum $m_{i \bullet}$ of the matrix $A$. Further, the element $m_{i_{0} j_{0}}=\frac{1}{V} m_{i_{0}} m_{\bullet} j_{0}$ is located in the place $\left(i_{0}, j_{0}\right)$ of the matrix M. Moreover, all rows of the matrix $M$ are proportional to the $i_{0}^{\text {th }}$ row, and the elements of this row are larger than the corresponding elements of all other rows. The same property applies to the $j_{0}^{\text {th }}$ column of the same matrix. Hence, the element located in $\left(i_{0}, j_{0}\right)$ defines the center of the largest cross within the matrix $M$. If this cross is excluded from $M$, then the second largest cross can be identified and so on. Thus, the matrix $M$ contains the rank-size sequence of crosses. One can reorganize the locations of rows and columns of $M$ in such a way that the centers of the corresponding crosses appear on the main diagonal. In this fashion, the matrix will be reorganized in such a way that a descending economic landscape will be apparent (see Figure 1). 
This rearrangement also reveals the descending rank-size hierarchies of the indices for direct forward and backward linkages. Inspection of that part of the landscape with indices $>1$ (the criterion for specification of direct inputs key sectors) will enable the identification of the key sectors (see Figure 2). However, it is important to stress that the construction of the economic landscape for different regions or for the same region at different points in time would create the possibility for the establishment of taxonomy of these economies. Moreover, the superposition of the hierarchy of one region on the landscape of another region provides a clear visual representation of the similarities and differences in the linkage structure of these regions.

It is important to stress, as will be shown in Section 6, that the Sraffian standard commodities-standard prices matrix $S$ coincides with the multiplier product matrix $M(S)$. Hence, the Sraffian matrix has the same cross-structure defined by rank-size hierarchies of components of vectors of standard commodities and standard prices (see Figure 3).

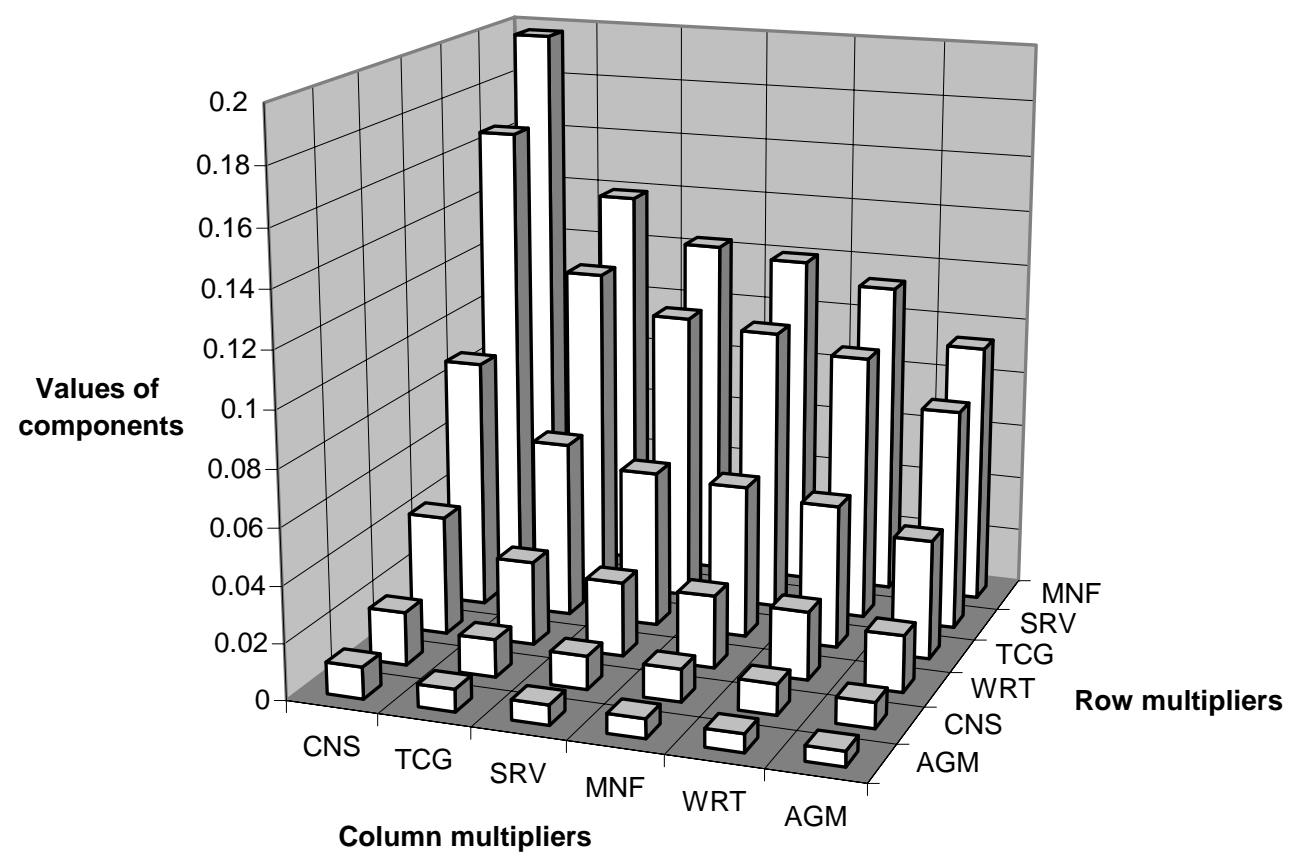

FIGURE 1. Economic Landscape for Chicago 1987 Input-Ouput Table 


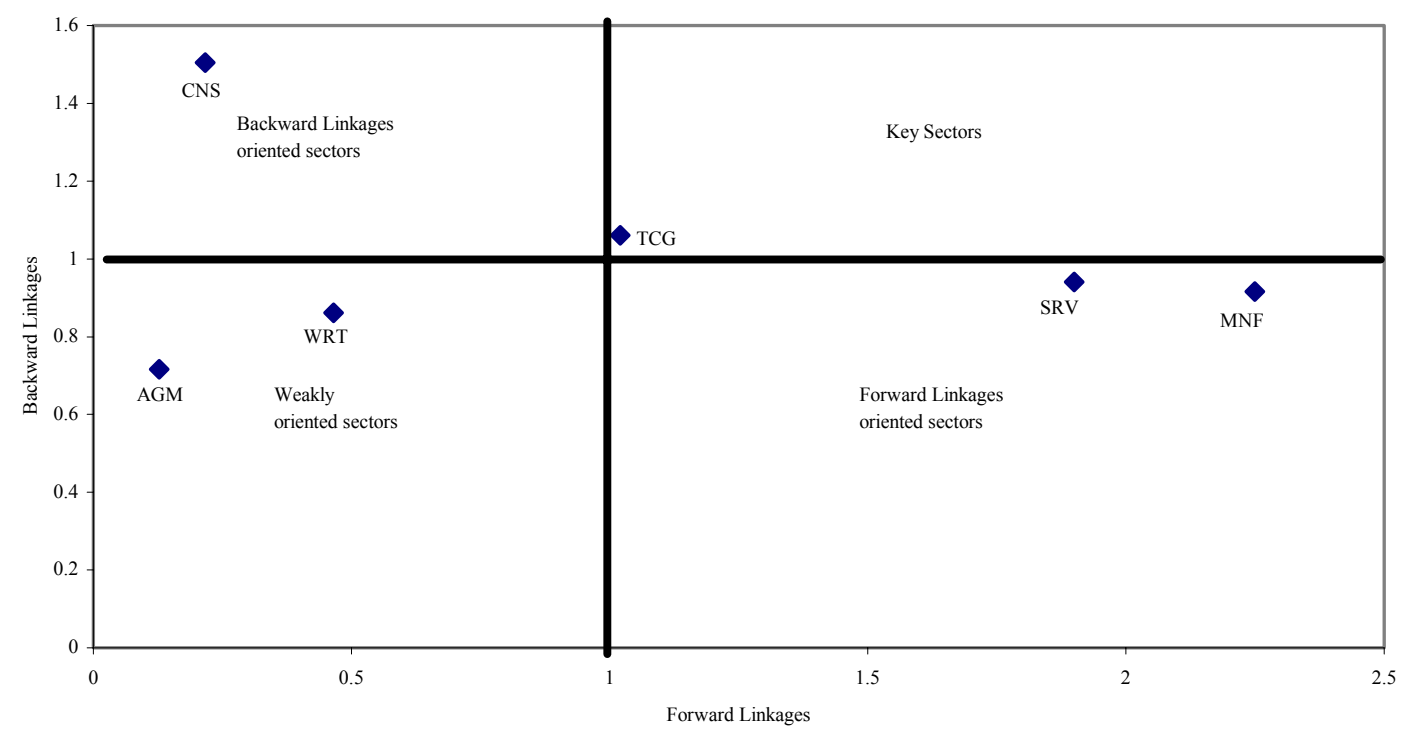

FIGURE 2. Direct Inputs Backward and Forward Linkages, Chicago, 1987

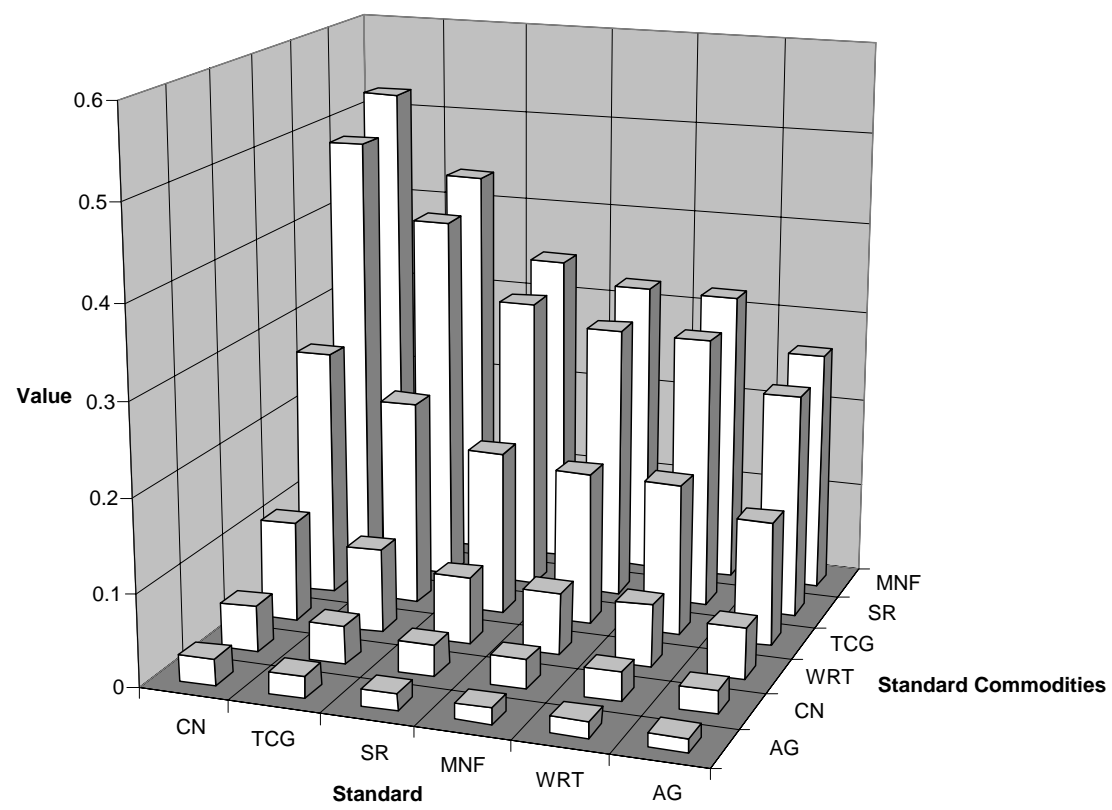

FIGURE 3. Economic Landscape of Sraffian Matrix 
The Review of Regional Studies, Vol. 37, No. 1, 2007, pp. 39 - 63

\section{MINIMUM INFORMATION PROPERTIES OF THE MPM AND $S$}

\subsection{Definition of Information of the Positive Matrix}

Consider all positive matrices, $\Psi=\left\lfloor\Psi_{i j}\right\rfloor$ with the property that the row and column multipliers are equal to those of the matrix $A$ :

$$
\sum_{j} \Psi_{i j}=m_{i}, \quad \sum_{i} \Psi_{i j}=m_{\bullet j} .
$$

Obviously, $\sum_{i, j} \Psi_{i j}=V$. We can convert each positive matrix $\Psi$ into the two-dimensional probabilistic distribution matrix, $P=[p(i, j)]$ with the components:

$$
p(i, j)=\Psi_{i j} / V
$$

Therefore, we can attribute to each positive matrix $\Psi$ the Shannon information (INF):

$$
I N F \Psi=I N F P=\sum_{i, j} p(i, j) \ln p(i, j)=\sum_{i, j} \frac{\psi_{i j}}{V} \ln \frac{\psi_{i j}}{V}
$$

\subsection{Minimum Information of MPM and S}

Recall the well-known Shannon information inequality (Shannon and Weaver 1964, p. 51):

$$
\sum_{i, j} p(i, j) \ln p(i, j) \geq \sum_{i, j} p(i, j) \ln \sum_{j} p(i, j)+\sum_{i, j} p(i, j) \ln \sum_{i, j} p(i, j) .
$$

This implies that each positive matrix $\psi$ satisfying the condition (39) may be shown as:

$$
\begin{aligned}
& I N F \Psi=\sum_{i, j} \frac{\Psi_{i j}}{V} \ln \frac{\Psi_{i j}}{V} \geq \sum_{i j} \frac{\Psi_{i j}}{V} \ln \sum_{j} \frac{\Psi_{i j}}{V}+\sum_{i j} \frac{\Psi_{i j}}{V} \ln \sum_{i j} \frac{\Psi_{i j}}{V}= \\
& =\sum_{i j} \frac{\Psi_{i j}}{V} \ln \frac{m_{i}}{V}+\sum_{i j} \frac{\Psi_{i j}}{V} \ln \frac{m_{\bullet}}{V}=\sum_{i}\left(\sum_{j} \frac{\Psi_{i j}}{V}\right) \ln \frac{m_{i} \bullet}{V}+\sum_{j}\left(\sum_{i} \frac{\Psi_{i j}}{V}\right) \ln \frac{m_{\bullet}}{V}= \\
& =\sum_{i} \frac{m_{i} \bullet}{V} \ln \frac{m_{i} \bullet}{V}+\sum_{j} \frac{m_{\bullet} j}{V} \ln \frac{m_{\bullet}}{V}=\sum_{i} \frac{m_{i}}{V^{2}}\left(\sum_{j} m_{\bullet j}\right) \ln \frac{m_{i} \bullet}{V}+\sum_{j} \frac{m_{\bullet} j}{V^{2}}\left(\sum_{i} m_{i} \cdot\right) \ln \frac{m_{\bullet} j}{V}= \\
& =\sum_{i j} \frac{m_{i} \cdot m_{\bullet} j}{V^{2}}\left(\ln \frac{m_{i} \cdot}{V}+\ln \frac{m_{\bullet} j}{V}\right)=\sum_{i j} \frac{m_{i} \cdot m_{\bullet j}}{V^{2}} \ln \frac{m_{i} \cdot m_{\bullet j}}{V^{2}}=I N F M \text {. }
\end{aligned}
$$


Then:

$$
I N F \Psi \geq I N F M
$$

and the multiplier product matrix $M$ has a minimal information property (Sonis 1968).

The matrix $M$ may be considered to represent the most homogeneous distribution of the components of the column and row sums of the matrix $A$. A further perspective may be offered; in the case of equal column and row sums, the economic landscape will be a flat, horizontal plane.

The MPM depends on the column and row sums only and thus represents only the aggregate characteristics of the direct interactions of each sector with the rest of the economy. Thus, the MPM does not take into account the specifics of the pair-wise sectoral interactions between direct inputs; the MPM can be considered as an aggregate representation of some sector equalization tendency in the economic interaction between sectors. Of course the same property of minimal information hold for the Sraffian matrix.

\section{PROPERTIES OF COLUMN AND ROW MULTIPLIERS OF THE PRODUCT OF POSITIVE MATRICES}

In the following, this important property of the multipliers of the product of two positive matrices will be used. Consider the product $A=A_{1} A_{2}=\left[a_{i j}\right]$ of two matrices $A_{1}=\left[a_{i j}^{1}\right], A_{2}=\left[a_{i j}^{2}\right]$. Let

$$
\begin{array}{ll}
m_{\bullet j}=\sum_{i=1}^{n} a_{i j}, & m_{i} \cdot=\sum_{j=1}^{n} a_{i j} \\
m_{\bullet j}^{1}=\sum_{i=1}^{n} a_{i j}^{1}, & m_{i \cdot}^{1}=\sum_{j=1}^{n} a_{i j}^{1} \\
m_{\bullet j}^{2}=\sum_{i=1}^{n} a_{i j}^{2}, & m_{i}^{2}=\sum_{j=1}^{n} a_{i j}^{2}
\end{array}
$$

be the column and row multipliers of these matrices. Let $V=\sum_{i j} a_{i j}$ be the global intensity of the matrix $A$. Further, specify the following vectors of column and row multipliers. 


$$
\begin{aligned}
& M_{c}(A)= {\left[m_{\bullet 1} m_{\bullet 2} \ldots m_{\bullet n}\right] ; M_{c}\left(A_{1}\right)=\left[m_{\bullet 1}^{1} m_{\bullet 2}^{1} \ldots m_{\bullet n}^{1}\right] ; M_{c}\left(A_{2}\right)=\left[m_{\bullet 1}^{2} m_{\bullet 2}^{2} \ldots m_{\bullet n}^{2}\right] } \\
& M_{r}(A)=\left[\begin{array}{l}
m_{1} \bullet \\
m_{2} \bullet \\
\vdots \\
m_{n}
\end{array}\right] ; M_{r}\left(A_{1}\right)=\left[\begin{array}{l}
m_{1}^{1} \bullet \\
m_{2}^{1} \bullet \\
\vdots \\
m_{n}^{1}
\end{array}\right] ; M_{r}\left(A_{2}\right)=\left[\begin{array}{l}
m_{1}^{2} \\
m_{2}^{2} \\
\vdots \\
m_{n}^{2}
\end{array}\right]
\end{aligned}
$$

The following formulae can be checked by direct calculations of the components of corresponding vectors and matrices.

$$
\begin{aligned}
& M_{c}(A)=M_{c}\left(A_{1}\right) A_{2} ; \\
& M_{r}(A)=A_{1} M_{r}\left(A_{2}\right) ; \\
& V(A)=M_{c}\left(A_{1}\right) M_{r}\left(A_{2}\right)
\end{aligned}
$$

\section{INTERCONNECTIONS BETWEEN MPM AND $S$}

It is obvious that the standardization condition of vectors $x^{*}$ and $p^{*}$ means that:

$$
M_{c}(S)=X p^{*} ; M_{r}(S)=P x^{*}
$$

where $X$ and $P$ are the sums of the components of vectors of standard commodities $X^{*}$ and standard prices $p^{*}$

$$
X=\sum_{i} x_{i}^{*} ; P=\sum_{i} p_{i}^{*}
$$

Thus, the multipliers of the Sraffian matrix $S$ are:

$$
M_{c}(S)=X p^{*} ; M_{r}(S)=P x^{*}
$$

and $V(A)=P X$. Hence, the multiplier product matrix of the Sraffian matrix coincides with the Sraffian matrix itself:

$$
M(S)=S
$$

Using this property and applying formulae (43) to the condition $A S=S A=\mu S$ one obtains:

$$
M_{c}(A) S=\mu X p^{*} ; S M_{r}(A)=\mu P x^{*} .
$$


This implies that

$$
M_{c}(A) X^{*}=\mu X ; p^{*} M_{r}(A)=\mu P
$$

or

$$
p^{*} M(A) X^{*}=\frac{\mu^{2} P X}{V}=\mu^{2}
$$

Further, using the well-known property of the row multipliers:

$$
M_{c}(A)=e-v_{a}
$$

where $e=(1,1, \ldots, 1)$ and vector $v_{a}$ is the vector of value added, the conditions (43) and (45) imply:

$$
\mu p^{*}=M_{r}(A) S=e S-v_{a} S=X p^{*}-v_{a} S
$$

or

$$
v_{a} S=(X-\mu) p^{*}
$$

The standardization (11) helps find the exact expression for vector of prices $p$ and vector of commodities $x$ that are the solutions of the Sraffian models: conditions $\mu p=p A$ and $\mu x=A x$ means that $p$ and $x$ are the eigenvectors of $A$ corresponding to the eigenvalue $\mu$. Therefore they are proportional to $p^{*}$ and $x^{*}$ :

$$
p=\alpha p^{*}, x=\beta x^{*}
$$

Introducing them into the standardization condition (11), one obtains $\alpha=\beta=1-\mu$, so the solutions for the Sraffa models are:

$$
p=(1-\mu) p^{*} ; x=(1-\mu) x^{*}
$$

Substituting (53) into (5) and (6), the decomposition of prices and commodities in SraffaLeontief models into three parts may be obtained, namely, an intermediate inputs part, an interest part, and a wage part:

$$
\begin{aligned}
& p=(1-\mu) p^{*}=(1-\mu) p^{*} A+r(1-\mu) p^{*} A+w^{*}(1-\mu) p^{*}(I-A) \\
& \mathrm{x}=(1-\mu) x^{*}=(1-\mu) A x^{*}+r(1-\mu) A x^{*}+w^{*}(1-\mu)(I-A) x^{*}
\end{aligned}
$$

\section{EXAMPLE}




\subsection{Multiplier Product Matrix for the Chicago Economy, 1987}

As an example, let us consider the $6 \times 6$ Chicago 1987 input-output table, aggregated from a 36-sector version. This table was derived from the Chicago Region Econometric Input-Output Model (CREIM), details on which can be found in Israilevich et al. (1997). Table 1 presents the sector definition for the Chicago table, and Table 2 presents the aggregated table itself together with the column and row multipliers, the direct inputs backward and forward indices, and their rank-size hierarchies.

Table 2 represents the matrix of direct inputs $A$ from the Primary and Dual SraffaLeontief models (6) and (7). The column and row multipliers of the matrix $A$ define the Multiplier Product matrix, calculated with the help of the formula (31) (see Table 3).

Rearranging the columns and rows of this matrix according the rank-size hierarchies of column and row sums, Table 4 will be revealed; this is the numerical presentation of the economic landscape visualized graphically in Figure 1. The spatial presentation of the hierarchies of backward and forward linkages of the matrix $A$ is presented in the space of backward and forward linkages in Figure 2. If a time series of matrices is available, such a representation will be useful for the description of the temporal dynamics of these linkages.

\subsection{Sraffian Matrix for the Chicago Economy in 1987}

The column sums from Table 2, defined with the help of (10), reveal the interval that includes the maximal Perronean eigenvalue: $0.2501<\mu<0.5261$. The actual value of this maximal eigenvalue is $\mu=0.3367$, so the maximal rate of profits in Chicago 1987 economy is

$$
r_{\max }=\frac{1-\mu}{\mu}=1.97
$$

The left-hand and right-hand eigenvectors corresponding to this eigenvalue are: standard prices eigenvector,

$$
p^{*}=[0.7398,1.464,0.905,1.219,0.89086,0.9704], P=6.1968
$$


TABLE 1

Chicago 1987 Input-Output Table Sectors Definitions

\begin{tabular}{|c|c|c|c|}
\hline \multicolumn{2}{|c|}{ Sectors } & \multirow[b]{2}{*}{ Description } & \multirow[b]{2}{*}{ SIC codes } \\
\hline Aggregate & Original & & \\
\hline \multirow{3}{*}{$A G M$} & 1 & Livestock and Other Agricultural Products & 01,02 \\
\hline & 2 & Forestry and Fishery; Agricultural Services & 07-09 \\
\hline & 3 & Mining & $10-14$ \\
\hline CNS & 4 & Construction & $15-17$ \\
\hline \multirow[t]{21}{*}{$M N F$} & 5 & Food and Kindred Products & 20 \\
\hline & 6 & Tobacco Manufactures & 21 \\
\hline & 7 & Textiles and Apparel & $22-23$ \\
\hline & 8 & Lumber and wood Products & 24 \\
\hline & 9 & Furniture and Fixtures & 25 \\
\hline & 10 & Paper and Allied Products & 26 \\
\hline & 11 & Printing and Publishing & 27 \\
\hline & 12 & Chemicals and Allied Products & 28 \\
\hline & 13 & Petroleum Refining and Related Industries & 29 \\
\hline & 14 & Rubber and Miscellaneous Plastics & 30 \\
\hline & & Products & \\
\hline & 15 & Leather and Leather Products & 31 \\
\hline & 16 & Stone, Clay, Glass and Concrete Products & 32 \\
\hline & 17 & Primary Metal Industries & 33 \\
\hline & 18 & Fabricated Metal products & 34 \\
\hline & 19 & Machinery, Except Electrical & 35 \\
\hline & 20 & Electrical and Electronic Machinery & 36 \\
\hline & 21 & Transportation Equipment & 37 \\
\hline & 22 & Scientific Instruments, Photographic and & 38 \\
\hline & & Medical Goods & \\
\hline & 23 & Miscellaneous Manufacturing Industries & 39 \\
\hline \multirow[t]{3}{*}{ TCG } & 24 & Transportation and Warehousing & $40-42,44-47$ \\
\hline & 25 & Communication & 48 \\
\hline & 26 & Electric, Gas and Sanitary Services & 49 \\
\hline WRT & 27 & Wholesale and Retail Trade & $50-57,59$ \\
\hline \multirow[t]{10}{*}{$S R V$} & 28 & Finance and Insurance & $60-64,67$ \\
\hline & 29 & Real Estate and Rental & 65,66 \\
\hline & 30 & Hotels, Personal and Business Services & $\begin{array}{c}70-73,76 \\
81,89\end{array}$ \\
\hline & 31 & Eating and Drinking Places & 58 \\
\hline & 32 & Automobile Repair and Services & 75 \\
\hline & 33 & Amusement and Recreation Services & 78,79 \\
\hline & 34 & Health, Educational and Nonprofit & $80,82-84,86$ \\
\hline & & Organizations & \\
\hline & 35 & Federal Government Enterprises & \\
\hline & 36 & State and Local Government Enterprises & \\
\hline
\end{tabular}


TABLE 2

Chicago 1987 Direct Inputs Table

\begin{tabular}{|c|c|c|c|c|c|c|c|c|c|}
\hline Sectors & AGM & CNS & MNF & $\mathrm{TCG}$ & WRT & SRV & Row Sums & $\begin{array}{c}\text { Forward } \\
\text { Linkages } \\
\text { DIFL } \\
\end{array}$ & $\begin{array}{c}\text { Rank-Size } \\
\text { Hierarchy } \\
\text { of DIFL }\end{array}$ \\
\hline $\mathrm{AGM}$ & 0.0195 & 0.0025 & 0.0101 & 0.0104 & 0.0011 & 0.0012 & 0.0447 & 0.1280 & VI \\
\hline $\mathrm{CNS}$ & 0.0273 & 0.0008 & 0.0049 & 0.0245 & 0.0054 & 0.0129 & 0.0758 & 0.2168 & $\mathrm{~V}$ \\
\hline MNF & 0.0867 & 0.3109 & 0.1707 & 0.0889 & 0.0475 & 0.0816 & 0.7863 & 2.2497 & I \\
\hline $\mathrm{TCG}$ & 0.0245 & 0.0381 & 0.0381 & 0.1542 & 0.0600 & 0.0418 & 0.3567 & 1.0205 & III \\
\hline WRT & 0.0245 & 0.0631 & 0.0385 & 0.0153 & 0.0133 & 0.0150 & 0.1697 & 0.4856 & IV \\
\hline SRV & 0.0676 & 0.1106 & 0.0582 & 0.0776 & 0.1740 & 0.1760 & 0.6639 & 1.8995 & II \\
\hline $\begin{array}{l}\text { Column sums } \\
\text { Backward }\end{array}$ & 0.2501 & 0.5261 & 0.3204 & 0.3708 & 0.3011 & 0.3287 & & & \\
\hline Linkages DIBL & 0.7156 & 1.5051 & 0.9166 & 1.0608 & 0.8615 & 0.9403 & & & \\
\hline $\begin{array}{l}\text { Rank-Size } \\
\text { Hierarchy of } \\
\text { DIBL }\end{array}$ & VI & I & IV & II & V & III & & & \\
\hline
\end{tabular}


TABLE 3

Multiplier Product Matrix for Chicago 1987

[direct inputs input-output table]

\begin{tabular}{|c|c|c|c|c|c|c|c|c|}
\hline Sectors & AGM & CNS & MNF & $\mathrm{TCG}$ & WRT & SRV & $\begin{array}{l}\text { Row } \\
\text { sums }\end{array}$ & $\begin{array}{c}\text { Rank-Size } \\
\text { Hierarchy of } \\
\text { Row Sums }\end{array}$ \\
\hline AGM & 0.00534 & 0.01124 & 0.00684 & 0.00792 & 0.00643 & 0.00702 & 0.0448 & VI \\
\hline CNS & 0.00904 & 0.01902 & 0.01158 & 0.01340 & 0.01088 & 0.01188 & 0.0758 & $\mathrm{~V}$ \\
\hline MNF & 0.09377 & 0.19725 & 0.12013 & 0.13902 & 0.11289 & 0.12324 & 0.7863 & I \\
\hline TCG & 0.04254 & 0.08948 & 0.05450 & 0.06307 & 0.05121 & 0.05591 & 0.3567 & III \\
\hline WRT & 0.02024 & 0.04257 & 0.02593 & 0.03000 & 0.02436 & 0.02660 & 0.1697 & IV \\
\hline SRV & 0.07917 & 0.16655 & 0.10143 & 0.11738 & 0.09532 & 0.10406 & 0.6639 & II \\
\hline Column Sums & 0.25010 & 0.52610 & 0.32040 & 0.37080 & 0.30110 & 0.32870 & & \\
\hline Rank-Size & & & & & & & & \\
\hline $\begin{array}{l}\text { Hierarchy of } \\
\text { Column Sums }\end{array}$ & VI & $\mathrm{I}$ & IV & II & $\mathrm{V}$ & III & & \\
\hline
\end{tabular}


TABLE 4

Economic Landscape for Chicago 1987 Multiplier Product Matrix.

\begin{tabular}{|c|c|c|c|c|c|c|c|c|}
\hline Sectors & CNS & $\mathrm{TCG}$ & SRV & MNF & WRT & AGM & Row Sums & $\begin{array}{l}\text { Rank-Size } \\
\text { Hierarchy of } \\
\text { Row Sums }\end{array}$ \\
\hline SRV & 0.16655 & 0.11738 & 0.10406 & 0.10143 & 0.09532 & 0.07917 & 0.6639 & II \\
\hline $\mathrm{TCG}$ & 0.08948 & 0.06307 & 0.05591 & 0.05450 & 0.05121 & 0.04254 & 0.3567 & III \\
\hline WRT & 0.04257 & 0.03000 & 0.02660 & 0.02593 & 0.02436 & 0.02024 & 0.1697 & IV \\
\hline Column sums & 0.52610 & 0.37080 & 0.32870 & 0.32040 & 0.30110 & 0.25010 & & \\
\hline Rank-Size & & & & & & & & \\
\hline $\begin{array}{l}\text { Hierarchy of } \\
\text { Column Sums }\end{array}$ & I & II & III & IV & V & VI & & \\
\hline
\end{tabular}


and standard commodities eigenvector,

$$
x^{*}=\left[\begin{array}{c}
0.0192 \\
0.0341 \\
0.3568 \\
0.1875 \\
0.0746 \\
0.3308
\end{array}\right], X=1,{ }^{*} p^{*} x^{*}=1 \quad\left[\begin{array}{l}
0.0192 \\
0.0341 \\
0.3568 \\
0.1875 \\
0.0746 \\
0.3308
\end{array}\right], X=1, p^{*} x^{*}=1
$$

The Sraffian matrix of standard commodities, standard prices for Chicago 1987 economy are presented in Table 5. The corresponding economic landscape for this matrix is shown in Figure 3.

These tables will help us to calculate the decompositions (54) of prices and commodities in Sraffa-Leontief models into three parts: an intermediate inputs part, an interest part, and a wage part (cf. Steenge 1997, pp. 244-247). This is shown in the Appendix.

\section{CONCLUSIONS AND FURTHER EXPLORATIONS}

This paper has revealed an important connection between the Sraffa-Leontief system and some new interpretations afforded by the multiplier product matrix. The properties of the latter matrix offer the potential for comparative analysis across time (for a single economy) or across economies at one point in time. Recently, some further considerations have explored an expansion of the Sraffa-Leontief models by considering a closed system of the Miyazawa-type in which profits and wages are distributed and their impacts on the economy are traced (see Miyazawa 1976; Kimura, Sonis, and Hewings 2002; Sonis and Hewings 2001). In this sense, the work of Trigg (1999), examining a link between Keynes, Morishima, and Miyazawa, provides further motivation for the potentially new and innovative insights that can be gained by exploring connections between modeling systems. 
TABLE 5

Sraffian Matrix for Chicago 1987 Direct Inputs Input-Output Table

\begin{tabular}{|c|c|c|c|c|c|c|c|c|c|}
\hline Sectors & AGM & CNS & MNF & $\mathrm{TCG}$ & WRT & SRV & $\begin{array}{c}\text { Standard } \\
\text { Commodities } \\
x^{*} \\
\end{array}$ & $\begin{array}{c}\text { Row } \\
\text { Multipliers } \\
P X^{*} \\
\end{array}$ & $\begin{array}{c}\text { Rank-Size } \\
\text { Hierarchy of } \\
x^{*} \\
\end{array}$ \\
\hline AGM & 0.014204 & 0.028104 & 0.017376 & 0.023405 & 0.017253 & 0.018632 & 0.0192 & 0.118979 & VI \\
\hline CNS & 0.025277 & 0.049922 & 0.030861 & 0.041568 & 0.030642 & 0.033091 & 0.0341 & 0.211311 & V \\
\hline MNF & 0.263961 & 0.522355 & 0.322904 & 0.434939 & 0.320620 & 0.346239 & 0.3568 & 2.211018 & I \\
\hline $\mathrm{TCG}$ & 0.136423 & 0.270108 & 0.166973 & 0.224906 & 0.165792 & 0.179039 & 0.1875 & 1.143310 & III \\
\hline WRT & 0.055189 & 0.109214 & 0.067513 & 0.090937 & 0.067036 & 0.072392 & 0.0746 & 0.462281 & IV \\
\hline SRV & 0.244726 & 0.484291 & 0.299374 & 0.403245 & 0.297257 & 0.321008 & 0.3308 & 2.049901 & II \\
\hline $\begin{array}{l}\text { Column } \\
\text { Multipliers }\end{array}$ & & & & & & & & & \\
\hline$X p^{*}$ & 0.739800 & 0.464000 & 0.905000 & 1.219000 & 0.898600 & 0.970400 & & & \\
\hline Standard & & 1.464000 & & 1.219000 & & & & & \\
\hline Prices $\mathrm{p}^{*}$ & 0.739800 & & 0.905000 & & 0.898600 & 0.970400 & & & \\
\hline Rank-Size & & & & & & & & & \\
\hline $\begin{array}{l}\text { Hierarchy of } \\
p^{*}\end{array}$ & VI & I & IV & II & V & III & & & \\
\hline
\end{tabular}


Sonis/Hewings: On the Sraffa-Leontief Model

\section{REFERENCES}

Chenery, H.B. and T. Watanabe, 1958. "International Comparisons of the Structure of Production," Econometrica 26, 487-521.

Goodwin, R.M., 1983. Essays in Linear Economic Structures. Macmillan: London.

Horn, R.A. and C.A. Johnson, 1985. Matrix Analysis. Cambridge University Press: Cambridge.

Israilevich, P.R., G.J.D. Hewings, M. Sonis, and G.R. Schindler, 1997. "Forecasting Structural Change with a Regional Econometric Input-Output Model," Journal of Regional Science 37, 565-590.

Kimura, Y., M. Sonis, and G.J.D. Hewings, 2002. "The Miyazawa-Sraffa-Leontief Model," in G.J.D. Hewings, M. Sonis, and D. Boyce (eds.). Trade, Networks and Hierarchies: Integrated Approaches to Modeling Regional and Interregional Economies. Springer Verlag: New York, Heidelberg.

Kurz, H.D. and N. Salvadori, 1995. Theory of Production: A Long Period Analysis. University Press: Cambridge.

Miyazawa, K., 1976. Input-Output Analysis and the Structure of Income Distribution. Springer Verlag: New York.

Pasinetti, L.L., 1977. Lectures on Theory of Production. Columbia University Press: New York.

Rasmussen, P., 1956. Studies in Inter-Sectoral Relationships. Einar Harks: Copenhagen.

Shannon, C.E. and W. Weaver, 1964. The Mathematical Theory of Communications. University of Illinois Press: Urbana.

Sonis, M., 1968. "Significance of Entropy Measures of Homogeneity for the Analysis of Population Redistributions," Geographical Problems, Mathematics in Human Geography 77, 44-63 (in Russian).

Sonis, M. and G.J.D. Hewings, 1999. "Economic Landscapes: Multiplier Product Matrix Analysis for Multiregional Input-Output Systems," Hitotsubashi Journal of Economics 40, 59-74.

, 2001. "An Expanded Miyazawa Framework: Labor and Capital Income, Saving, Consumption and Investment Links," in D. Felsenstein, R. McQuaid, P. McCann, and D. Shefer (eds.), Public Investment and Regional Economic Development, Edward Elgar.

Sonis, M., G.J.D. Hewings, and J. Guo, 2000. "A New Image of Classical Key Sector Analysis: Minimum Information Decomposition of the Leontief Inverse," Economic Systems Research 12, 401-423.

Sraffa, P., 1960. Production of Commodities by Means of Commodities. Cambridge University Press: Cambridge.

Steenge, A.E., 1995. "Sraffa and Goodwin: A Unifying Framework for Standards of Value in the Income Distribution Problem," Journal of Economics 62, 55-75.

, 1997. "The Elusive Standard Commodity: Eigenvectors as Standards of Value," in A. Simonovits and A.E. Steenge (eds.), Prices, Growth and Cycles. Essays in Honor of Andreas Brody. Macmillan Press: London.

Trigg. A.B., 1999. "An Interindustry Analysis of the Relationship Between Marx and Keynes," in G.J.D. Hewings, M. Sonis, M. Madden, and Y. Kimura (eds.) 
Understanding and Interpreting Economic Structure. Springer-Verlag: Heidelberg, 145-153.

\section{APPENDIX}

\section{Decomposition of the Sraffian matrix}

$0.6633[0.7398,1.464,0.905,1.219,0.89086,0.9704]=$

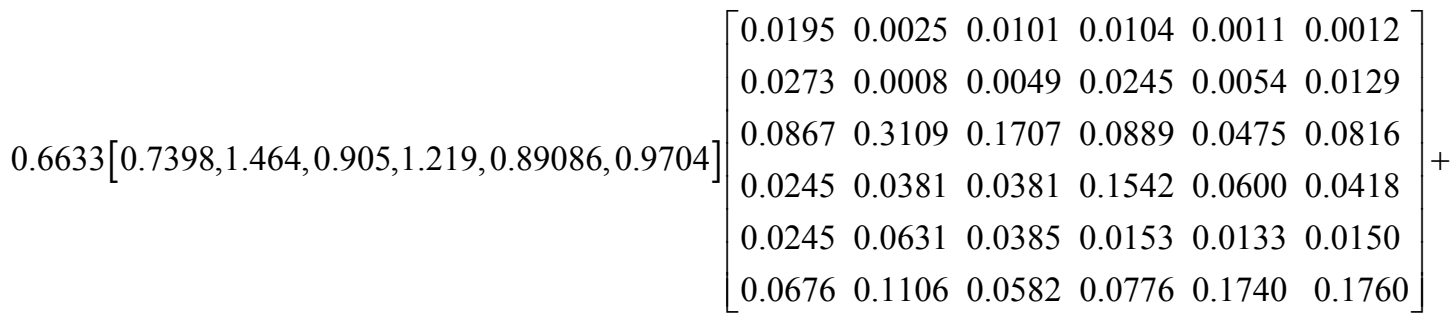
$+r 0.6633[0.7398,1.464,0.905,1.219,0.89086,0.9704]\left[\begin{array}{cccccc}0.0195 & 0.0025 & 0.0101 & 0.0104 & 0.0011 & 0.0012 \\ 0.0273 & 0.0008 & 0.0049 & 0.0245 & 0.0054 & 0.0129 \\ 0.0867 & 0.3109 & 0.1707 & 0.0889 & 0.0475 & 0.0816 \\ 0.0245 & 0.0381 & 0.0381 & 0.1542 & 0.0600 & 0.0418 \\ 0.0245 & 0.0631 & 0.0385 & 0.0153 & 0.0133 & 0.0150 \\ 0.0676 & 0.1106 & 0.0582 & 0.0776 & 0.1740 & 0.1760\end{array}\right]+$ $+w^{*} 0.6633[0.7398,1.464,0.905,1.219,0.89086,0.9704]\left[\begin{array}{rrrrrr}0.9805 & -0.0025 & -0.0101 & -0.0104 & -0.0011 & -0.0012 \\ -0.0273 & 0.9992 & -0.0049 & -0.0245 & -0.0054 & -0.0129 \\ -0.0867 & -0.3109 & 0.8293 & -0.0889 & -0.0475 & -0.0816 \\ -0.0245 & -0.0381 & -0.0381 & 0.8458 & -0.0600 & -0.0418 \\ -0.0245 & -0.0631 & -0.0385 & -0.0153 & 0.9867 & -0.0150 \\ -0.0676 & -0.1106 & -0.0582 & -0.0776 & -0.1740 & 0.8240\end{array}\right]$; $0.6633\left[\begin{array}{l}0.0192 \\ 0.0341 \\ 0.3568 \\ 0.1875 \\ 0.0746 \\ 0.3308\end{array}\right]=0.6633\left[\begin{array}{cccccc}0.0195 & 0.0025 & 0.0101 & 0.0104 & 0.0011 & 0.0012 \\ 0.0273 & 0.0008 & 0.0049 & 0.0245 & 0.0054 & 0.0129 \\ 0.0867 & 0.3109 & 0.1707 & 0.0889 & 0.0475 & 0.0816 \\ 0.0245 & 0.0381 & 0.0381 & 0.1542 & 0.0600 & 0.0418 \\ 0.0245 & 0.0631 & 0.0385 & 0.0153 & 0.0133 & 0.0150 \\ 0.0676 & 0.1106 & 0.0582 & 0.0776 & 0.1740 & 0.1760\end{array}\right]\left[\begin{array}{l}0.0192 \\ 0.0341 \\ 0.3568 \\ 0.1875 \\ 0.0746 \\ 0.3308\end{array}\right]+$ 


$+r 0.6633\left[\begin{array}{llllll}0.0195 & 0.0025 & 0.0101 & 0.0104 & 0.0011 & 0.0012 \\ 0.0273 & 0.0008 & 0.0049 & 0.0245 & 0.0054 & 0.0129 \\ 0.0867 & 0.3109 & 0.1707 & 0.0889 & 0.0475 & 0.0816 \\ 0.0245 & 0.0381 & 0.0381 & 0.1542 & 0.0600 & 0.0418 \\ 0.0245 & 0.0631 & 0.0385 & 0.0153 & 0.0133 & 0.0150 \\ 0.0676 & 0.1106 & 0.0582 & 0.0776 & 0.1740 & 0.1760\end{array}\right]\left[\begin{array}{l}0.0192 \\ 0.0341 \\ 0.3568 \\ 0.1875 \\ 0.0746 \\ 0.3308\end{array}\right]+$

$+w^{*} 0.6633\left[\begin{array}{cccccc}0.9805 & -0.0025 & -0.0101 & -0.0104 & -0.0011 & -0.0012 \\ -0.0273 & 0.9992 & -0.0049 & -0.0245 & -0.0054 & -0.0129 \\ -0.0867 & -0.3109 & 0.8293 & -0.0889 & -0.0475 & -0.0816 \\ -0.0245 & -0.0381 & -0.0381 & 0.8458 & -0.0600 & -0.0418 \\ -0.0245 & -0.0631 & -0.0385 & -0.0153 & 0.9867 & -0.0150 \\ -0.0676 & -0.1106 & -0.0582 & -0.0776 & -0.1740 & 0.8240\end{array}\right]\left[\begin{array}{l}0.0192 \\ 0.0341 \\ 0.3568 \\ 0.1875 \\ 0.0746 \\ 0.3308\end{array}\right]$

